\title{
A comparative analysis of pressure sore treatment modalities in community settings
}

\author{
N Small; M Mulder; MJ Mackenzie \& M Nel
}

\section{Introduction}

The management of pressure sores in community settings, poses a clinical problem which challenges the patient's tolerance and the clinician's diligence and ingenuity. Pressure sores can be painful, lead to infection and are associated with considerable morbidity and increased mortality (Patterson \& Bennett, 1995:919; Bale, Banks, Hagelstein \& Harding, 1998:65). Treatment costs of these wounds are high in terms of resources (Colin 1995:65; Wood, Griffiths \& Stoner, 1997:256). However, since there are untold cost in terms of pain and suffering to the patient, it is impossible to calculate the true cost of pressure sores (Dealey, 1994:87).

Patients in a community setting are as vulnerable to sustaining pressure sores as those in hospital (James, 1997:12). Several community risk factors are likely to present problems to skin integrity, namely immobility and unrelieved pressure, malnutrition, age, incontinence and chronic illness. Due to the increase in the ageing population and the associated higher degree of morbidity, along with the emphasis on provision of care shifting towards the earlier discharge of acutely ill patients, it is expected that the number of patients at risk for developing pressure sores in the community will increase (Inman \& Firth, 1998:515; Glover, 2000:161). This phenomenon will add to the at-risk-population in the community, thereby placing a greater demand on community resources as a result of an increase in the incidence of pressure sores. Consequently it is clear that the most cost-effective and acceptable method of wound management is needed to address the problem of large numbers of pressure sores in the community.

The most important aspects of managing patients with pressure sores include relieving pressure and shear force or friction, promoting continence and maximizing nutrition and fluid intake. However, local wound management does have an important role to play. A cost-effective method of wound management implies a method that will result in rapid wound healing. Since Winter's landmark research (1962:294) it has been recognized that a moist wound environment promotes reepithelialisation and healing, thereby supporting cost-effective wound care management. Despite this evidence many clinicians still use alternative treatment methods that cause desiccation of the wound-bed and thereby impede the healing process.

Since wound healing is an intricate and dynamic process, it has been suggested that no single dressing is suitable for the management of all wounds, particularly at all stages of the healing process (Bux \& Malhi, 1996:305). However, the majority of modern dressings are now designed to maintain a moist environment at the wound interface, providing conditions for rapid epithelialisation and thereby improved healing (Frantz \&
Gardner, 1994:39; Bux \& Malhi, 1996:305; Dale, 1997:12). Though many of these modern dressings are more expensive than traditional cellulose-based products, very often wounds dressed with newer products, heal more rapidly than those dressed with conventional materials resulting in cost savings (Thomas, 1997).

The choice of dressing or treatment method may be influenced by several factors - a major one being the cost. Another influence on the choice of dressing or treatment method is its acceptability to patients and caregivers. Often patients with chronic wounds and their caregivers have firm views on the dressings that they will accept based upon prior experience with these or similar materials (Thomas, 1997).

Controlled clinical wound care trials are an important part of evaluating the performance of wound dressing materials and provide research-based information to nurses and clinicians striving to establish effective treatment strategies (Banks \& Bale, 1994:301).

\section{Purpose}

The purpose of this research was to compare current wound care management methods with a more advanced wound care method using three Smith \& Nephew ${ }^{\mathrm{TM}}$ wound care products, in the treatment of patients with pressure sores in the community over a six week period.

\section{Objectives}

Specific objectives included comparison of cost-effectiveness with regard to treatment cost and rate of healing as well as assessment of the acceptability of these treatment modalities to patients and caregivers in terms of ease of application, comfort of the dressing, durability and ease of removal. Information regarding wound sites and patient characteristics was also collected.

\section{Research design}

Of the nine main experimental designs available to the nurse researcher, as identified by Bums and Grove (1993:317-323), a prospective randomized, controlled trial was best suited to phenomenon under investigation. This experimental design may further be classified as an open-label clinical trial since both the researcher and the patients knew the nature of the treatment.

In support of the chosen design the following was noted. Experimental designs provide a significant amount of control in order to examine causality more closely. It has also been proposed that this technique be used to examine areas of nursing 
practice, such as comparing traditional nursing care practices with newer techniques (Burns \& Grove, 1993:323).

\section{Population}

\section{Patient recruitment}

Patients were recruited via referrals from primary health care clinics, community health care workers and other health care professionals practicing in the community. Several patient recruitment strategies were used namely:

Communicating with colleagues directly, via E-mail and telephone requesting referrals.

- $\quad$ Speaking at formal and informal professional meetings requesting referrals.

- $\quad$ Placing notices in places where colleagues and/or patients would see them.

- $\quad$ Placing advertisements in local newspapers.

Over a twelve-month period (from May 1999 to June 2000), a total of 60 patients were screened for inclusion to the study, of whom 58 patients met the inclusion criteria and were considered suitable for entry.

\section{Inclusion criteria}

- $\quad$ Patients in the Bloemfontein community aged 18 years or older with a clinically uninfected Stage 2, 3 or 4 pressure sore. (The Stirling Pressure Sore Severity Scale (Waterlow, 1996:56) was used as classification system)

- Patients or their guardians, who gave informed consent.

- $\quad$ Patients who were willing and able to comply with the treatment.

\section{Randomisation}

Eligible patients were randomised into an equally sized control- and experimental group. Randomisation was done by pressure sore Stage, according to a computer generated randomisation list provided by the Department Biostatistics, University of the Free State. If a patient had more than one pressure sore, all sores were treated with the same treatment modality. However, only one sore was chosen at random for inclusion in the study and it was on the basis of this sore's classification, that randomisation occurred. In order to select a sore at random, the sores were numbered from top (superior) to bottom (inferior), left to right and a random number selected from a random number table.

Unlike institution-based studies, community-based studies do not allow for larger sample sizes without certain implications (Bale \& Banks. 1994:304). These implications refer to practical issues, such as variable control and the financial implications of extensive community-based studies that require additional skilled field workers. In view of these implications and the documented successes of smaller comparable studies by Bale and co-workers (1997:463 and 1998:65), it was decided in collaboration with biostatisticians that a sample of at least 40 patients was a statistically adequate number.

\section{Treatment modality}

Two treatment modalities were used namely: an advanced wound care management method (using Smith \& Nephew ${ }^{\mathrm{TM}}$ products) for patients in the experimental group and the currently used management method for patients in the control group.

\section{Advanced wound care management}

The peri-wound area was cleansed with a gentle, hypoallergenic soap and water to remove any excessive exudate and transient micro-organisms from the surrounding skin and dried with gauze. The wounds were than aseptically cleansed with warm (approximately $37^{\circ} \mathrm{C}$ ) sterile, physiological saline. A gentle cleansing technique was used by either irrigation, if the wound had delicate granulation tissue, or by gently patting the wound bed.

The three trial dressings were the following:

A hydrogel (IntraSite ${ }^{\mathrm{TM}}$ gel)

A foam dressing (Allevyn ${ }^{\text {TM }}$ hydrocellular polyurethane sheets or Allevyn ${ }^{\mathrm{TM}}$ adhesive)

A transparent film dressing (OpSite Flexigrid ${ }^{\mathrm{TM}}$ )

Where non-viable tissue was present on the surface of the wound requiring debridement, a thin layer of IntraSite ${ }^{\mathrm{TM}}$ gel was applied on the wound bed and covered with either Allevyn $^{\mathrm{TM}}$ non-adhesive, hydrocellular sheets or Allevyn ${ }^{\mathrm{TM}}$ adhesive. If the wound was granulating and no non-viable tissue was present at the surface, then Allevyn ${ }^{\mathrm{TM}}$ non-adhesive hydrocellular sheets or Allevyn ${ }^{\mathrm{TM}}$ adhesive were applied directly to the wound. Transparent OpSite Flexigrid ${ }^{\mathrm{TM}}$ dressings were applied to Stage 2 epithelialising wounds. OpSite Flexigrid $^{\mathrm{TM}}$ was also used as a secondary dressing to secure Allevyn $^{\mathrm{TM}}$ non-adhesive dressings. All the selected dressings were applied to the wounds strictly according to the manufacturer's instructions.

\section{Currently used wound care management}

The peri-wound area was cleansed in the same way as those in the experimental group. The wound was then aseptically cleansed and covered with the available wound care materials and/or methods as used on that particular patient at that time by the patient or primary caregiver.

These materials included cleansers such as saline and water; a variety of disinfectants such as hypochlorite solutions (Milton, Eusol), hydrogen peroxide, cetrimide, chlorhexidine; antibacterial ointments and creams such as povidone iodine and silver sulfadiazine; systemic antibiotics such as metrinidazol that were crushed and sprinkled over the wound (bear in mind these were non-infected wounds); essential oils such as Tea Tree oil and St John's wort; pure honey; mixtures/potions that amongst others included a mixture of povidone-iodine, honey and chloramphenicol. Dressings included cotton wool, alginates, hyrocolloids, gauze impregnated dressings (medicated and non-medicated) and gauze.

In order to avoid cross-contamination and subsequent wound infection, the researcher maintained strict adherence, in both treatment modalities throughout the entire study, to the basic principles of asepsis and infection control, as recommended 
by the Agency for Health care Policy and Research (AHCPR) (1994:1-10). Similarly, throughout the study, the researcher provided continuous education and encouraged all patients and caregivers to adhere to the measures for pressure reduction, daily skin examination and intermittent pressure relief techniques as described in the Clinical Practice Guidelines by the AHCPR (1994:1-10). Additionally the researcher attempted, where possible, to address those identified factors that could delay wound healing. The frequency of dressing changes was determined by the unique nature and needs of each patient's wound.

\section{Period of treatment}

Each patient was managed for a period of six weeks or until one of the following end points were reached:

- $\quad$ the wound healed:

- $\quad$ the patient withdrew;

- an adverse event occurred in which the treatment benefit was unacceptably inferior to treatment risk.

\section{Data collection}

Wounds were assessed weekly and data collected using specifically designed data collection forms. Additionally four evaluation methods were used to assess the rate of wound healing namely:

- $\quad$ standardized digital wound photography;

- $\quad$ tracing of the wound edges;

- $\quad$ measurements of the wound and its appearance as well as

- descriptive field notes.

\section{Data analysis}

The data analysis included a cost analysis and statistical analysis. Cost-effectiveness was expressed by dividing the number of patients that healed into the total cost of treating that particular group. This indicated the cost of healing per patient healed.

Demographic and baseline information was summarized by group. Numeric variables were summarized by medians and percentiles as the distributions were skew. Categorical variables were summarized by frequencies and percentages. Changes between baseline and consecutive treatment week information were summarized per group by medians and percentiles or percentages, as appropriate for the difference between the groups, with $95 \%$ confidence intervals. The percentage of withdrawals and adverse events were compared between the two groups using 95\% confidence intervals for differences in percentages. The log-rank-survival test was used to calculate the percentage of patients that healed by the end of each week.

\section{Validity and reliability}

To increase the validity and reliability of the study, several approaches and techniques were applied. They included the following:

- Preliminary data collection forms were forwarded to four domain experts for comment regarding appropri -ateness, accuracy and representativeness of items on the forms. Once these comments were returned, appropriate changes to refine the forms were made thereby assuring content-related validity evidence.

- Mono-operation bias to assess wound healing was addressed by the use of multiple evaluation methods thereby improving the construct validity.

- Reliability of the instrument was improved through consistent use of it throughout the data collection process. This was facilitated by the use of only one data collector thereby avoiding bias and inconsistency and problems associated with interrater reliability.

- Random assignment to experimental and control groups was used as a design strategy to control extraneous variables and lack of equivalence.

- Patients were homogenous in terms of three extraneous variables namely the presence of an uninfected pressure sore, aged 18 years or older and living in the Bloemfontein community.

- A pilot study was undertaken which provided the researcher with the opportunity to test and improve the data collection forms and become familiar with the photographic equipment and technique.

The study and treatment methods were continuously monitored by an official, independent study monitor thereby improving the validity and reliability of the study.

\section{Ethical considerations}

The main ethical considerations referred to the right to selfdetermination, confidentiality and protection from harm.

Patients were asked to partake voluntarily and were only enrolled into the study with written informed consent, provided by themselves or their legal guardians, and where possible in collaboration with their attending physician(s). All participants were asked to sign a consent form, which contained a detailed description of the trial procedures and methods. Consent forms were available in the three main languages spoken within the Bloemfontein community namely Afrikaans, English and SouthSotho. In addition patients had the right to withdraw from the study at any time without penalty.

All patient names were kept confidential. The study number allocated to them during the study identified patients throughout the evaluation and documentation. Patients were carefully monitored and where any adverse event occurred, the patients were discontinued and managed appropriately.

The study was performed in accordance with the guidelines of the World Medical Association Declaration of Helsinki (1996) 
and continuously monitored by an official study monitor. After obtaining approval from the Ethics Committee, Faculty of Health Sciences, University of the Free State, the study was initiated.

\section{Results}

Sixty patients were screened for inclusion in the study, of whom 58 patients $(\mathrm{N}=58)$ were considered suitable for entry.
Randomisation resulted in 28 patients allocated to the experimental group and 30 patients to the control group. Base-line demographic data (See Table 1) acquired on entry were: gender, age, allergies, weight, height (body mass index) and wound site. Assessment data acquired on entry and thereafter at weekly intervals included: pressure sore risk assessment (using the Braden Risk Assessment Scale [Bergstrom, Demuth \& Braden, 1987:417]), wound duration since onset, wound dimensions, pressure sore stage, level of exudate, appearance of the wound

\section{Table 1: Base-line demographic data}

\begin{tabular}{|c|c|c|c|c|}
\hline Demographic data & \multicolumn{2}{|c|}{$\begin{array}{l}\text { Experimental group } \\
\qquad\left(n_{\mathrm{c}}=28\right)\end{array}$} & \multicolumn{2}{|c|}{$\begin{array}{l}\text { Control group } \\
\left(\mathrm{nt}_{\mathrm{c}}=3(1)\right)\end{array}$} \\
\hline Gender & Frequency & $\%$ & Frequency & $\%$ \\
\hline $\begin{array}{l}\text { Male } \\
\text { Female }\end{array}$ & $\begin{array}{l}7 \\
21\end{array}$ & $\begin{array}{l}(25 \%) \\
(75 \%)\end{array}$ & $\begin{array}{l}16 \\
14\end{array}$ & $\begin{array}{l}(53 \%) \\
(47 \%)\end{array}$ \\
\hline \multicolumn{5}{|l|}{ Allergies } \\
\hline $\begin{array}{l}\text { None } \\
\text { Morphine } \\
\text { Penicillin } \\
\text { Bee sting }\end{array}$ & $\begin{array}{l}27 \\
1 \\
0 \\
0\end{array}$ & $\begin{array}{l}(96,4 \%) \\
(3,6 \%)\end{array}$ & $\begin{array}{l}28 \\
0 \\
1 \\
1\end{array}$ & $\begin{array}{l}(93,3 \%) \\
(3,3 \%) \\
(3,3 \%)\end{array}$ \\
\hline \multicolumn{5}{|l|}{ Age } \\
\hline $\begin{array}{l}\text { Minimum } \\
\text { Median } \\
\text { Maximum } \\
{ }^{1} \text { C.I. } \quad[-10 ; 1]\end{array}$ & $\begin{array}{l}19 \mathrm{yrs} \\
76,5 \mathrm{yrs} \\
89 \mathrm{yrs}\end{array}$ & & $\begin{array}{l}24 \mathrm{yrs} \\
78 \mathrm{yrs} \\
97 \mathrm{yrs}\end{array}$ & \\
\hline \multicolumn{5}{|l|}{ Body mass index (BMI) } \\
\hline $\begin{array}{l}\text { Minimum } \\
\text { Median } \\
\text { Maximum } \\
\text { C.I. } \quad[-1,63 ; 2,07]\end{array}$ & $\begin{array}{l}17 \\
22 \\
27\end{array}$ & & $\begin{array}{l}13 \\
21 \\
28\end{array}$ & \\
\hline
\end{tabular}

${ }^{1} \mathrm{C} . \mathrm{I}$ indicates $95 \%$ confidence intervals for the median difference between the experimental and control groups 


\begin{tabular}{|c|c|c|c|c|}
\hline Demographic data & \multicolumn{2}{|c|}{$\begin{array}{l}\text { Experimental group } \\
\qquad\left(\mathrm{n}_{\mathrm{c}}=28\right)\end{array}$} & \multicolumn{2}{|c|}{$\begin{array}{l}\text { Control group } \\
\qquad\left(n_{\mathrm{c}}=30\right)\end{array}$} \\
\hline BMI Male Patients & Frequency & $\%$ & Frequency & $\%$ \\
\hline $\begin{array}{ll}\text { underweight } & <20 \\
\text { normal weight } & \leqslant 20 \text { and } \geqslant 25 \\
\text { overweight } & >25\end{array}$ & $\begin{array}{ll} & \quad(n= \\
2 & \\
5 & \\
0 & \end{array}$ & $\begin{array}{l}(28,6 \%) \\
(71,4 \%)\end{array}$ & $8 \quad(n=1$ & $\begin{array}{l}(50 \%) \\
(43,8 \%) \\
(6,2 \%)\end{array}$ \\
\hline BMI Female Patients & Frequency & $\%$ & Frequency & $\%$ \\
\hline $\begin{array}{ll}\text { underweight } & <19 \\
\text { normal weight } & \leqslant 19 \text { and } \geqslant 24 \\
\text { overweight } & >24\end{array}$ & $\begin{array}{ll} & (\mathrm{n}= \\
4 & \\
9 & \\
8 & \end{array}$ & $\begin{array}{l}(19,1 \%) \\
(42,9 \%) \\
(38 \%)\end{array}$ & $2 \quad(n=1$ & $\begin{array}{l}(14,3 \%) \\
(57,1 \%) \\
(28,6 \%)\end{array}$ \\
\hline Weight distribution & Frequency & $\%$ & Frequency & $\%$ \\
\hline $\begin{array}{l}\text { underweight } \\
\text { normal weight } \\
\text { overweight } \\
\text { (using the BMI as reference) }\end{array}$ & $\begin{array}{l}6 \\
14 \\
8\end{array}$ & $\begin{array}{l}(21,4 \%) \\
(50 \%) \\
(28,5 \%)\end{array}$ & $\begin{array}{l}10 \\
15 \\
5\end{array}$ & $\begin{array}{l}(33,3 \%) \\
(50 \%) \\
(16,6 \%)\end{array}$ \\
\hline Wound site & Frequency & $\%$ & Frequency & $\%$ \\
\hline Sacrum & 11 & $(39 \%)$ & 15 & $(50 \%)$ \\
\hline Trochanter & 6 & $(21,4 \%)$ & 6 & $(20 \%)$ \\
\hline Malleolus & 3 & $(10,7 \%)$ & 0 & - \\
\hline Iliac crest & 2 & $(7,1 \%)$ & 2 & $(6,7 \%)$ \\
\hline Ischium & 2 & $(7,1 \%)$ & 1 & $(3,3 \%)$ \\
\hline Heel & 2 & $(7,1 \%)$ & 3 & $(10 \%)$ \\
\hline Wrist & 1 & $(3,6 \%)$ & 0 & - \\
\hline Lat. side of foot & 1 & $(3,6 \%)$ & 0 & - \\
\hline Elbow & 0 & - & 2 & $(6,7 \%)$ \\
\hline Scapula & 0 & - & 1 & $(3,3 \%)$ \\
\hline
\end{tabular}


bed. surrounding skin/wound margin, pain, factors that may delay wound healing and medications used.

The majority of pressure sores in both the experimental group (70\%) and control group $(60,4 \%)$ were located on the sacrum or trochanters. However, the site with the highest frequency of ulceration was the sacrum. There were no significant differences between the two groups on entry therefore the two groups were equivalent in terms of demographic and prognostic factors and thus comparable. dents, defined as any undesirable clinical occurrence in a patient which was thought to be directly related to the investigational product(s), occurred.

\section{Healers and non-healers}

The total number of patients who completed the study, that is, healers and non-healers, was 41 . This represents $70,6 \%$ of the total study population $(\mathrm{N}=58)$.

\section{Table 2: Population $(\mathrm{N}=58)$ status at the end of the study period}

\begin{tabular}{|l|lc|lc|}
\hline \multicolumn{3}{|c|}{$\begin{array}{c}\text { Experimental group } \\
\left(\mathbf{n}_{\mathbf{c}}=\mathbf{2 8}\right)\end{array}$} & \multicolumn{2}{c|}{$\begin{array}{c}\text { Control group } \\
\left(\mathbf{n}_{\mathbf{c}}=\mathbf{3 0 )}\right.\end{array}$} \\
\hline Status & Frequency & $\%$ & Frequency & $\%$ \\
\hline Healed & 15 & $(53,6 \%)$ & 9 & $(30 \%)$ \\
Non-healers & 8 & $(28,6 \%)$ & 9 & $(30 \%)$ \\
Moved & 3 & $(10,7 \%)$ & 7 & $(23,3 \%)$ \\
Infected & 1 & $(3,6 \%)$ & 3 & $(10 \%)$ \\
Hospitalized & 1 & $(3,6 \%)$ & 1 & $(3,3 \%)$ \\
\hline
\end{tabular}

\section{Table 3 : Percentage healed by the end of each week}

\begin{tabular}{|c|c|c|}
\hline Week & $\begin{array}{l}\text { Experimental group } \\
\qquad\left(\mathrm{n}_{\mathrm{e}}=28\right)\end{array}$ & $\begin{array}{l}\text { Control group } \\
\left(n_{c}=\mathbf{3 0}\right)\end{array}$ \\
\hline 1 & $15.1 \%$ & $7,7 \%$ \\
\hline 2 & $22,8 \%$ & $15.8 \%$ \\
\hline 3 & $30,8 \%$ & $15,8 \%$ \\
\hline 4 & $39.4 \%$ & $30,9 \%$ \\
\hline 5 & $44.1 \%$ & $30,9 \%$ \\
\hline 6 & $59,2 \%$ & $37,2 \%$ \\
\hline
\end{tabular}

\section{Withdrawals}

Fifty-eight patients $(\mathrm{N}=58)$ were enrolled in the study in week zero. However, during the course of the six-week treatment period a total of $17(29,3 \%)$ patients were withdrawn as they died, moved from the geographical area, developed a wound infection or were hospitalized. (See Table 2) No adverse inci-
The wounds of a significant number of patients $15(53,6 \%)$ in the experimental group were healed as opposed to only $9(30 \%)$ in the control group. Notably all the wounds that healed in both groups were classified upon entry as stage two pressure sores. The log-rank-survival test was used to offset the higher death rate in the control group and make maximum use of all available patient data up to the point of withdrawal. Results of 
the log rank test, depicted in Table 3, indicate the percentage of patients healed by the end of each week. Although there appeared to be a faster rate of healing in the experimental group than in the control group, the difference was not statistically significant $(\mathrm{p}=0.15)$. An almost equal number of patients in both groups [ $8(28,6 \%)$ in the experimental group and $9(30 \%)]$ remained for the entire study duration but did not achieve healing.
The total cost of treating patients in the control group who completed the study was R22 824.71. Nine out of 18 patients in this group were completely healed. When dividing the healed group (9) into the total treatment cost, the cost to achieve healing in the control group was $\mathbf{R} 2536.08$ per patient. Similarly the $95 \%$ confidence interval, [1644.4; 3427.7], here indicates the range of treatment cost for the control group only. Since the values of the confidence intervals for the re-

\section{Table 4: Patients'assessment of dressing application and removal}

\begin{tabular}{|c|c|c|c|c|}
\hline Assessment & \multicolumn{2}{|c|}{$\begin{array}{l}\text { Experimental group } \\
\qquad\left(\mathbf{n}_{\mathrm{c}}=23\right)\end{array}$} & \multicolumn{2}{|c|}{$\begin{array}{c}\text { Control group } \\
\left(n_{\mathrm{c}}=18\right)\end{array}$} \\
\hline $\begin{array}{l}\text { 'Application of the dressing was } \\
\text { easy' }\end{array}$ & Frequency & $\%$ & Frequency & $\%$ \\
\hline Agree strongly & 11 & $(47,8 \%)$ & 1 & $(5,6 \%)$ \\
\hline Agree a lot & 9 & $(39,1 \%)$ & 2 & $(11,1 \%)$ \\
\hline Tend to agree & 2 & $(8,7 \%)$ & 10 & $(55,6 \%)$ \\
\hline Tend to disagree & 1 & $(4,3 \%)$ & 5 & $(27,8 \%)$ \\
\hline Disagree a lot & 0 & - & 0 & - \\
\hline Disagree strongly & 0 & - & 0 & - \\
\hline $\begin{array}{l}\text { 'Removal of the dressing was } \\
\text { difficult' }\end{array}$ & Frequency & $\%$ & Frequency & $\%$ \\
\hline Agree strongly & 0 & - & 0 & - \\
\hline Agree a lot & 0 & - & 0 & - \\
\hline Tend to agree & 0 & - & 0 & - \\
\hline Tend to disagree & 1 & $(4,3 \%)$ & 10 & $(55,6 \%)$ \\
\hline Disagree a lot & 7 & $(30,4 \%)$ & 6 & $(33,3 \%)$ \\
\hline Disagree strongly & 15 & $(65,2 \%)$ & 2 & $(11,1 \%)$ \\
\hline
\end{tabular}

\section{Comparison of treatment cost}

Despite the fact that there were no significant differences between the two groups as far as cost is concerned, it is evident from the $95 \%$ confidence interval $[-789.75 ; 159.12]$ that there was a tendency for the control group to have higher values indicating that the control treatments tended to be more expensive than the experimental treatment.

\section{Cost-effectiveness}

The total cost of treating patients in the experimental group who completed the study was R23 052.02. Fifteen out of 23 patients in this group were completely healed. By dividing the healed group (15) into the total treatment cost ( $R 23$ 052.02) the cost of achieving healing was $\mathbf{R} 1 \mathbf{5 3 6 . 0 8}$ per patient in the experimental group. The $95 \%$ confidence interval, [869.1; 2204.5], here indicates the range of treatment cost for the experimental group only. spective groups overlap, there was no statistically significant difference between the groups as far as cost-effectiveness was concerned. However, there does appear to be a tendency for the control treatment to be more expensive and thus less costeffective than the experimental treatment.

\section{Dressing acceptability}

The acceptability of the wound treatment method to patients and caregivers was assessed on completion of the study period by means of a structured questionnaire.

\section{Patients' assessment of dressing acceptability}

Patients indicated their responses to specific statements related to the comfort of the dressings on application and removal (See Table 4$)$. Fourteen $(60,9 \%)$ of patients in the experi- 
mental group agreed that application was comfortable as opposed to only $6(33,4 \%)$ patients in the control group. No one in the experimental group experienced discomfort on dressing removal. However, one $(5,6 \%)$ patient in the control group expressed strong discomfort on dressing removal. Notably a large number of patients $[9(39,1 \%)$ in the experimental group and 11 $(61,1 \%)$ in the control group] could not report on the comfort of the dressing, as they were unresponsive due to age-related dementia. tal group were significantly more durable than those used in the control group: $95 \%$ confidence interval [60,5; 94,2].

\section{Conclusion}

From the results it may be concluded that over a six-week period more wounds in the experimental group, treated with advanced wound care products and in particular three Smith \& Nephew ${ }^{\mathrm{TM}}$ products, healed, than wounds in the control group

\section{Table 5: Caregiver's assessment of dressing application and removal}

\begin{tabular}{|c|c|c|c|c|}
\hline Assessment & \multicolumn{2}{|c|}{$\begin{array}{l}\text { Experimental group } \\
\qquad\left(n_{\mathrm{e}}=23\right)\end{array}$} & \multicolumn{2}{|c|}{$\begin{array}{c}\text { Control group } \\
\left(\mathbf{n}_{\mathrm{c}}=18\right)\end{array}$} \\
\hline $\begin{array}{l}\text { 'Application of the dressing was } \\
\text { easy' }\end{array}$ & Frequency & $\%$ & Frequency & $\%$ \\
\hline Agree strongly & 11 & $(47,8 \%)$ & 1 & $(5,6 \%)$ \\
\hline Agree a lot & 9 & $(39,1 \%)$ & 2 & $(11,1 \%)$ \\
\hline Tend to agree & 2 & $(8,7 \%)$ & 10 & $(55,6 \%)$ \\
\hline Tend to disagree & 1 & $(4,3 \%)$ & 5 & $(27,8 \%)$ \\
\hline Disagree a lot & 0 & - & 0 & - \\
\hline Disagree strongly & 0 & - & 0 & - \\
\hline $\begin{array}{l}\text { 'Removal of the dressing was } \\
\text { difficult' }\end{array}$ & Frequency & $\%$ & Frequency & $\%$ \\
\hline Agree strongly & 0 & - & 0 & - \\
\hline Agree a lot & 0 & - & 0 & - \\
\hline Tend to agree & 0 & - & 0 & - \\
\hline Tend to disagree & 1 & $(4,3 \%)$ & 10 & $(55,6 \%)$ \\
\hline Disagree a lot & 7 & $(30,4 \%)$ & 6 & $(33,3 \%)$ \\
\hline Disagree strongly & 15 & $(65,2 \%)$ & 2 & $(11,1 \%)$ \\
\hline
\end{tabular}

\section{Caregiver's assessment of dressing acceptability}

The overall ease of dressing application in the experimental group was much higher. This was shown to be statistically significant: $95 \%$ confidence interval $[1,6 ; 47,7]$. Although the caregiver did not find it difficult to remove any dressings, it does appear that dressing removal in the experimental group was easier than in the control group (See Table 5).

\section{Caregiver's assessment of dressing durability}

Dressing durability over the six-week treatment period was assessed by means of a rating scale. The scale ranged form one (not durable) to five (extremely durable). The assessment showed that dressings used to treat patients in the experimen- treated with the currently available wound care products.

As there were no significant statistical differences between the groups with regard to the cost to achieve healing, it may be assumed that the advanced wound care treatment method was not more expensive than the currently used methods. However, there was a tendency for the currently used methods to be more expensive. Furthermore, when cost of treatment for all patients who completed the study (healers and non-healers) was compared results indicated a tendency for the advanced treatment method, using the three Smith \& Nephew ${ }^{\text {TM }}$ products, to be less expensive. Consequently it may be concluded that the results of this study indicate a trend for advanced wound care methods to be more cost-effective than currently used methods. Although these trends were not statistically 
significant, they could be of clinical and practical importance.

With regard to acceptability of dressings in terms of ease as well as comfort of application and removal, the majority of patients in the experimental group rated their dressings as acceptable. In contrast only a third of patients in the control group rated their dressings as acceptable. Finally, the caregiver's assessment of dressing acceptability in terms of ease of application and removal as well as durability over the six-week period indicate that dressings used in the advanced wound care management method (Smith $\&$ Nephew ${ }^{\mathrm{TM}}$ products) were significantly more acceptable than dressings used in the current management methods.

\section{Recommendations}

It appears that the advanced treatment method lends itself to better wound care practice with potentially financial benefits to individuals and institutions, yet there is still a tendency for currently used traditional treatment methods to persist. Consequently a paradigm shift towards a more advanced wound care treatment method is needed. However, this will require training and education about wound care to patients, caregivers and all health care professionals.

During the 12-month data collection period of this study the researcher saw evidence of an alarming lack of knowledge with regard to all aspects related to the basic principles of pressure sore prevention and treatment, not only in patients and caregivers but also health care workers which included professional nurses and physicians. The development of a comprehensive best practice model for pressure sore prevention and treatment in community settings could be of an enormous value to wound care practitioners and significantly benefit patients with pressure sores in the community.

Despite advances in wound care products and much international research on the topic over the past decade, a literature search revealed no published community-based wound care trials in South Africa. As such this study accentuated the need for more clinical research in wound care in South Africa.

\section{References}

AGENCY FOR HEALTH CARE POLICY AND RESEARCH (AHCPR) 1994: Clinical Practice Guideline. Pressure Ulcers in Adults: Prediction and Prevention. U.S. Department of Health and Human Services. AHCPR Publication No. 92-0050.

BALE, S., BANKS, V., HAGELSTEIN, S. \& HARDING, K. G. 1998. A comparison of two amorphous hydrogels in the debridement of pressure sores. Journal of Wound Care. 7(2): 65-68.

BALE, S., SQUIRES, D., VARNON, T., WALKER, A., BENBOW, M. \& HARDING, K. 1997. A comparison of two dressings in pressure sore management. Journal of Wound Care. 61 10): 463-466.

BANKS, V. \& BALE, S. 1994. Practical problems of undertaking clinical trials in the community. Journal of Wound Care. 3(6): 301-304.
BERGSTROM, N., DEMUTH,P.J. \& BRADEN, B. J. 1987. A clinical trial of the Braden Scale for predicting pressure sore risk. Nursing Clinics of North America. 22(2): 417-428.

BURNS, N. \& GROVE, S. K. 1993. The Practice of Nursing Research. $2^{\text {nd }}$ edition. Philadelphia: W. B. Saunders Company.

BUX, M. \& MALHI, J.S. 1996. Assessing the use of dressings in practice. Journal of Wound Care.5(7): 305-308.

COLIN, P. 1995. A healing regime. Nursing Times. 9I(5): 65-68.

DALE, J. 1997. Wound dressings. Professional Nurse Supplement. 12(12): 12-14.

DEALEY, C. 1994. The Care of Wounds. London: Blackwell Scientific Publications.

FRANTZ, R A \& GARDNER, S 1994: Elderly skin care. Principles of chronic wound care. Journal of Gerontological Nursing. 20(9): $35-44$.

GLOVER, D: 2000. Infection control: Everyone's responsibility. Journal of Wound Care, 9(4): 161

INMAN, I. \& FIRTH, J. R. 1998. Pressure sore prevalence in the community. Professional Nurse. 13(7): 515-520.

JAMES, H. 1997. Preventing pressure sores in patients' homes. Professional Nurse Study Supplement. 12(6): 12-14.

PATTERSON, J. A. \& BENNETT, R. G. 1995 Prevention and treatment of pressure sores. Journal of the American Geriatrics Society. 43(8): 919-927.

SPILKER, B. 1991. Guide to Clinical Trials. Raven Press: New York.

THOMAS, S. 1997. A structured approach to the selection of dressings. The Electronic Journal of Wound Management Practice.

http://www.smtl.co.uk/World-Wide-Wounds/1997/ julyThomas-Guide/Dress-Select.html

WATERLOW, J. 1996. Pressure sore assessments. Nursing Times. 92(29): 53-58.

WINTER, G. D. 1962. Formation of the scab and the rate of epithelialization of superficial wounds in the skin of the young domestic pig. Nature. 193: 293-294.

WOOD, F., GRIFFITHS, T. A. \& STONER, M. 1997. Epidermal-derived factors in the treatment of a leg ulcer. Journal of Wound Care. 6(6): 256-258.

WORLD MEDICAL ASSOCIATION. 1996. Declaration of Helsinki. Recommendations guiding physicians in biomedical research involving human subjects as amended by the $48^{\text {th }}$ General Assembly, Somerset West. Republic of South Africa, October 1996. 